\title{
Factor Structure and Psychometric Properties of the Work-Family Balance Scale in an Urban Chinese Sample
}

\author{
Huiping Zhang • Paul S. F. Yip • Peilian Chi $\cdot$ Kinsun Chan • \\ Yee Tak Cheung $\cdot$ Xiulan Zhang
}

Accepted: 12 December 2010/Published online: 4 January 2011

(C) The Author(s) 2011. This article is published with open access at Springerlink.com

\begin{abstract}
The purpose of this study was to explore the factor structure of the WorkFamily Balance Scale (WFBS) and examine its reliability and validity in use in the urban Chinese population. The scale was validated using a sample of 605 urban Chinese residents from 7 cities. Exploratory factor analysis identified two factors: work-family conflict and work-family enrichment. The WFBS showed adequate reliability and concurrent validity. The WFBS is a reliable and valid instrument to measure work-family balance for Chinese working parents. However, further examination of the scale is needed.
\end{abstract}

Keywords Psychometric properties - Urban Chinese - Work-family balance · Work-family conflict · Work-family enrichment

\section{Introduction}

Work-family balance is a core issue for both married adults' wellbeing and organizational development, and the lynchpin of a healthy and well-functioning society (Halpern 2005). As

\footnotetext{
H. Zhang $(\bowtie) \cdot$ P. Chi

Department of Social Work and Social Administration, The University of Hong Kong, Pokfulam Road, Hong Kong, SAR PR China

e-mail: zhp07@hku.hk

P. S. F. Yip

Department of Social Work and Social Administration, Center for Suicide Research and Prevention, The University of Hong Kong, Pokfulam Road, Hong Kong, SAR PR China

K. Chan

Department of Government and Public Administration, University of Macau,

Av. Padre Tomas Pereira, Taipa, Macao, SAR PR China

Y. T. Cheung

Center for Suicide Research and Prevention, The University of Hong Kong, Pokfulam Road, Hong Kong, SAR PR China

X. Zhang

School of Social Development and Public Policy, Beijing Normal University, Beijing, China
} 
an indictor of quality of life, work-family balance has gained both academic and practical attention in the United States (Barnett, et al. 2004), European countries (McGinnity and Whelan 2009), and Japan (Gornick et al. 2007). However, it is also particularly meaningful to investigate this issue in contemporary urban China. That is because:

Firstly, balancing work and family has become a critical issue in urban China against a backdrop of globalization and social modernization. As China is transforming into a market-oriented economy, the interference between the work and family domains is becoming serious ( $\mathrm{Lu}$ et al. 2009; Siu et al. 2005). Extensive evidence shows that indicators of work-family balance are associated with greater job and marital satisfaction (Allen et al. 2000; Kossek and Ozeki 1999). On the other hand, the absence of work-family balance is positively associated with job stress (Behson 2002), individual health and wellbeing (Frone 2000; Frone et al. 1997; Grzywacz and Bass 2003; Major et al. 2002).

Secondly, unlike the traditional role specialization of domestic and agricultural work between the two sexes in rural China as the popular saying "nan geng nv zhi" (men till the land and women weave cloth), it is quite common that both men and women work outside home in urban China, and the labor force participation rates for fathers and mothers with children aged 0-6 in 2004 were 90.6 and 71.3\% respectively (Du and Dong 2008). Such a high percentage of working parents makes the performance of roles in both the work and family context crucial for most adults living in Chinese cities, and a concern for their wellbeing as they negotiate this balance in practice is timely.

Thirdly, China represents a unique setting, which is particularly appropriate to the task of validating existing work-family balance theories. China differs dramatically from Western cultures in its strong emphasis on collectivism and family (Lai 1995), prevailing adoption of the one-child policy and closer ties with extended family members who can provide social support for family responsibilities (Spector et al. 2007).

Considering these issues, it is important to develop a cultural sensitive tool in measuring the work-family balance for urban Chinese. The applicability of the current scale on workfamily balance used in the western societies for urban China has yet to be determined.

It is very timely indeed to study this important but under-researched area in China which has experienced rapid urbanization in the past three decades. It will facilitate not only individual-level well-being but also national-level policy intervention for fostering a harmonious society.

\section{Work-Family Balance: Conceptualization and Measurement}

Before discussing the work-family balance, it is necessary to review how this construct is conceptualized.

Work-family balance has not been consistently defined despite widespread academic and practical interest. Most work-family researchers view work-family balance as the absence of work-family conflict, or the frequency and intensity in which work interferes with family or family interferes with work (Grzywacz and Carlson 2007 for review). Until recently, work-family balance has been operationalized in terms of positive effects of integrating work and family roles, namely, work-family enrichment (Frone 2003). And it has also been shown that work-family conflict and work-family enrichment are independent constructs rather than opposite ends of a single continuum (Aryee et al. 2005; Voydanoff 2004).

To advance the conceptualization on the concept of work-family balance, Grzywacz and Carlson (2007) defined work-family balance as the accomplishment of role-related 
expectations that are negotiated and shared between an individual and his or her rolerelated partner in the work and family domains, which has received wide recognition. According to Grzywacz and his colleague, work-family balance has two dimensions: workfamily conflict (WFC) and work-family enrichment (WFE), which include four specific components: work-to-family conflict, family-to-work conflict, work-to-family enrichment, and family-to-work enrichment. This component approach can foster a full understanding of work-family balance in terms of both positive and negative aspect, and make the construct clearer and easier to interpret, which will contribute to richer theory of work and family. Therefore, this approach is adopted in our present study.

Compared with the theoretical discussion over the concept of work-family balance, there has been limited empirical study on its validation work. One primary method to assess work-family balance in previous work is the overall evaluation with one item (see and), however, the problems inherent in this approach have been criticized. The second method is to integrate two separately validated WFC (Carlson et al. 2000; Netemeyer et al. 1996) and WFE (Carlson et al. 2006) scales, which is extremely limited because of the longevity of the questionnaire and the amount of trivial factors.

Work-Family Strains and Gains (Marshall and Barnett 1993) is an appropriate measure to capture work-family balance as conceptualized above. The original 26-item version was developed based on open-ended interviews with 403 employed women (Marshall and Barnett 1991) and four factors were identified, namely work-family gains (WFG), workfamily strains (WFS), work-parenting gains (WPG), and work-parenting strains (WPS). This scale has good reliability and validity for both men and women, and fully captures the essence of the work-family balance as defined in this paper. A revised, shortened version (13 items) has been used in the Household, Income and Labor Dynamics (HILDA) panel survey in Australia (Wooden 2003). To measure the work-family balance construct concisely and promote the utility of this scale, we adopt the short version in our study.

The purpose of the present study is therefore to explore the factor structure of the workfamily balance scale (WFBS) and its psychometric properties with specific reference to reliability and concurrent validity. This study could contribute to the literature in two important ways. First, conceptualization of work-family balance as including both workfamily conflict and work-family enrichment, especially the latter, is theoretically informative because of the relatively limited research on the positive aspect of work-family balance. Second, since work-family balance scale is developed originally in the West, it is of great value to extend this scale to a Chinese sample with different cultures in providing evidence of generalization.

\section{Methods}

\subsection{Participants}

The validation of the instrument was carried out as part of a larger study, the Chinese Urban Household Survey, conducted by the Institute of Social Development and Public Policy at Beijing Normal University in 2004. The multistage sample consisted of 1,749 households in 7 large Chinese cities (Lanzhou, Wuhan, Nanchang, Taiyuan, Guangzhou, Shenyang, and Chongqing). These were purposefully selected to represent Chinese social, economic, and geographical contexts at different levels. Sampled households were approached with the help of local government officials, with three community residents' committees being selected in each city. 300 households were randomly selected from these 
Table 1 Demographic characteristics of the participants $(N=605)$

\begin{tabular}{lrc}
\hline & Frequency & Percentage \\
\hline Gender & & \\
Male & 312 & 51.6 \\
Female & 293 & 48.4 \\
Age & & \\
$<=30$ & 63 & 10.4 \\
$31-45$ & 339 & 56.0 \\
$>=46$ & 203 & 33.6 \\
Whether having children under 18 & \\
Yes & 399 & 66.0 \\
No & 206 & 34.0 \\
Place & & \\
Chongqing & 46 & 7.6 \\
Lanzhou & 122 & 20.2 \\
Wuhan & 101 & 16.7 \\
Nanchang & 90 & 14.9 \\
Taiyuan & 138 & 22.8 \\
Guangzhou & 80 & 13.2 \\
Shenyang & 28 & 4.6 \\
\hline
\end{tabular}

committees to participate in the survey. If the selected household was not available at the time of the visit, it was replaced by that of the next-door neighbor. Overall, about $10 \%$ of the sample consisted of neighbor replacements. Our analysis is based on 605 first-married respondents who reported their work-family balance experiences in the year preceding the interview.

Of the participants, $51.6 \%$ were male. The sample covered a wide range in terms of age distribution; $10.4 \%$ was 30 years or less, $56 \%$ between 31 and 45 , and $33.6 \%$ over $46.66 \%$ of the respondents had children under 18. In terms of location, the respondents came from Chongqing (7.6\%), Lanzhou (20.2\%), Wuhan (16.7\%), Nanchang (14.9\%), Taiyuan (22.8\%), Guangzhou (13.2\%), and Shenyang (4.6\%). The demographic characteristics of the sample are presented in Table 1.

\subsection{Instruments}

\subsubsection{The Chinese Kansas Marital Satisfaction Scale (CKMSS)}

The KMSS was developed by Schumm and colleagues (1986) and has been validated in urban China (Li and Chen 2002). It includes 3 items, namely; (1) "Generally speaking, are you satisfied with your marriage?"; (2) "Are you satisfied with your spouse?"; and (3) "Are you satisfied with the relationship between you and your spouse?" Respondents are asked to rate each item on a 5-point Likert scale ranging from 1 (extremely dissatisfied) to 5 (extremely satisfied). A higher score reflects a higher degree of marital satisfaction.

\subsubsection{Job Satisfaction}

This was measured by a single-item question, "Overall, how satisfied are you with your job?” Responses ranged from 1 (very dissatisfied) to 5 (very satisfied), with a higher score 
reflecting greater job satisfaction. A single item measuring overall satisfaction has been argued as superior to the approach of summing up facet scales, because the latter may neglect some components of a job that are important to an employee (Wanous et al. 1997).

\subsubsection{Mental Health}

This was measured using the mental health summary indicator from the SF-36 Health Survey (Ware 2000). Five specific questions were used to derive the mental health index, namely; (1) "Have you been a nervous person?"; (2) "Have you felt so down in the dumps that nothing could cheer you up?"; (3) "Have you felt calm and peaceful?"; (4) "Have you felt down?"; (5) "Have you been a happy person?" Respondents were asked to indicate how often they had experienced those feelings in the last 4 weeks by rating items on a 5 -point Likert scale that ranged from 1 (never to 5 (all the time)). However, our panel experts agreed that it was difficult to distinguish between the meaning of questions two and four in the Chinese version, so only the former was included in this study. Before the analysis, questions two and three were recoded. The higher the score, the better the respondent's mental health.

\subsubsection{Work Stress}

This was measured by a single-item question, namely "I feel my work unimaginably stressful." Response ranged from 1 (totally disagree) to 5 (totally agree). A high score indicated higher work stress.

\section{Results}

\subsection{Factor Structure}

Exploratory factor analysis (EFA) was conducted to identify the latent structure of the 13-item WFBS. Before conducting the EFA, we tested several of the statistical assumptions necessary for such an analysis. The Kaiser-Meyer-Olkin index of sampling adequacy was 0.74 , indicating that partial correlations were small and that the matrix was suitable for factor analysis (Tabachnick and Fidell 2001). Bartlett's test of sphericity was statistically significant $\left(\chi^{2}=1,763.72, d f=78, p<.001\right)$, and no evidence of multicollinearity or singularity was found (Tabachnick and Fidell 2001). These results showed that the EFA could be adequately performed. In order to determine the number of factors to retain, two methods were utilized; eigenvalues greater than 1, and factors that lay above the elbow of the scree plot (Cattell 1966).

Initial examination of the items using principal component analysis with varimax rotation to maximize variance, revealed three factors having an eigenvalue greater than one. However, the scree plot result suggested a two-factor solution. Subsequent analyses resulted in the emergence of a two-factor component structure as the most meaningful and interpretable solution. This was supported by a scree plot which indicated a sharp break after two components.

The two factors so identified accounted for $43.56 \%$ of the total variance. Judged by item content, the first factor comprised the combination of the negative aspects of Marshall's original scale, namely WFS and WPS, so it was labeled as WFC to match the 
Table 2 Factor structure of the work-family balance scale

\begin{tabular}{ll}
\hline Item & $\begin{array}{l}\text { Factor } \\
\text { loading }\end{array}$ \\
\cline { 2 - 3 } & I II
\end{tabular}

Factor I: Work-family conflict $(23.49 \%)$

1. My work cost me something I should have had as a parent (item 13)

$.70-.09$

2. Because of family responsibility, I have more pressure than fun at work (item 5)

$.70-.03$

3. My work reduces my time and energy to be a parent more than I expected (item 12)

$.69-.08$

4. Because of work, I often fail to take part in family activities (item 6)

.69

5. Because of work, I feel more pressure than fun at home (item 7)

$.63-.12$

6. Because of family responsibility, I have to give up opportunities or jobs that I like (item 4)

$.53 \quad .14$

7. I worry about my children when I am working (item 11) (Eigenvalue $=3.05$, Range $=7-35, \mathrm{M}=21.25, \mathrm{SD}=4.63$ )

Factor II: Work-family enrichment $(20.07 \%)$

8. Work and family together enrich my life (item 2)

9. Work and family together make my life complete (item 1)

10. Balance between work and family makes me feel I am strong (item 3)

11. My work makes me a better father/mother (item 10)

12. Work makes me cherish being with my children (item 9)

13. My work has a positive effect on my children (item 8 ) (Eigenvalue $=2.61$, Range $=6-30, \mathrm{M}=22.97, \mathrm{SD}=3.18$ )

$\%$ In parentheses was the amount of variance explained by each factor $M$ mean value of the sample on this scale, $S D$ standard deviation

conceptualization of the WFBS. The second factor combined the positive aspects of Marshall's original scale, that is, WFG and WPG, so for the same reason it was labeled as WFE. The rotated component structure of the scale, factor loadings, and the mean scale value for each subscale are presented in Table 2.

As Table 2 shows, there was no item with a factor loading of less than 0.40 or crossloading, so all 13 items were retained.

\subsection{Reliability}

The Cronbach's alpha coefficient was calculated to determine the internal consistency of the total scale and subscale of the WFBS. It was 0.69 for the total score, 0.75 for WFC, and 0.71 for WFE, indicating adequate internal consistency. To further understand the relationships of these measures, the inter-correlations among them were also computed, the results indicating that the two factors were highly correlated with the total score $\left(\mathrm{r}_{1}=.83\right.$, $\left.p<.01 ; \mathrm{r}_{2}=.58, p<.01\right)$ but not with each other $(\mathrm{r}=.03, p>.05)$.

\subsection{Preliminary Analyses}

Preliminary analyses were conducted to examine whether the WFBS score varied according to the demographic characteristics, and the results are presented in Table 3.

Comparison using the ANOVA test found no gender difference in either WFC or WFE, but there was an age difference in the latter; respondents aged 31-45 reported a better 
Table 3 Descriptive characteristics of WFC and WFE

\begin{tabular}{|c|c|c|c|c|c|c|}
\hline Variables & $\begin{array}{l}\text { Work- } \\
\text { family } \\
\text { conflict }\end{array}$ & $\begin{array}{l}\text { Test } \\
\text { statistic }\end{array}$ & $\begin{array}{l}\text { Post hoc } \\
\text { test }\end{array}$ & $\begin{array}{l}\text { Work- } \\
\text { family } \\
\text { enrichment }\end{array}$ & Test statistic & $\begin{array}{l}\text { Post hoc } \\
\text { test }\end{array}$ \\
\hline Gender & & $\mathrm{F}=.88$ & & & $\mathrm{~F}=.09$ & \\
\hline Male & $21.44(4.39)$ & & & $22.93(3.02)$ & & \\
\hline Female & $21.06(4.88)$ & & & $23.01(3.34)$ & & \\
\hline Age group & & $\mathrm{F}=2.72$ & $2>3$ & & $\mathrm{~F}=3.29^{*}$ & $1,2>3$ \\
\hline 1. $<=30$ & $22.03(4.78)$ & & & $23.70(2.81)$ & & \\
\hline 2. $31-45$ & $21.55(4.46)$ & & & $23.16(3.12)$ & & \\
\hline 3. $>=46$ & $20.64(4.63)$ & & & $22.52(3.28)$ & & \\
\hline $\begin{array}{l}\text { Whether having children } \\
\text { under } 18\end{array}$ & & $\mathrm{~F}=3.92 *$ & $2>1$ & & $\mathrm{~F}=.43$ & \\
\hline 1. No & $20.63(4.55)$ & & & $22.82(3.14)$ & & \\
\hline 2. Yes & $21.50(4.65)$ & & & $23.02(3.20)$ & & \\
\hline Place & & $\mathrm{F}=3.45^{* *}$ & $\begin{array}{c}2>1,3 \\
4,7>1 \\
3,5\end{array}$ & & $\mathrm{~F}=5.60 * * *$ & $\begin{array}{c}1,3>4 \\
6,7 \\
2>4,7\end{array}$ \\
\hline 1. Chongqing & $19.90(6.08)$ & & & $24.05(3.68)$ & & \\
\hline 2. Lanzhou & $21.93(4.39)$ & & & $23.11(2.99)$ & & \\
\hline 3. Wuhan & 20.17 (4.67) & & & $23.54(3.06)$ & & \\
\hline 4. Nanchang & $22.38(4.63)$ & & & $22.10(3.33)$ & & \\
\hline 5. Taiyuan & $20.82(4.56)$ & & & $23.46(2.71)$ & & \\
\hline 6. Guangzhou & $21.25(3.90)$ & & & $22.20(3.04)$ & & \\
\hline 7. Shenyang & $23.04(3.47)$ & & & $20.84(3.80)$ & & \\
\hline
\end{tabular}

$* p<.05 ; * * p<.01$

work-family balance than those aged 46 and over. There was a parenthood difference in WFC, but not WFE. Parents reported more WFC than did married but childless adults. Differences in both WFC and WFE by city-level were also significant. To be specific, urban residents in Nanchang and Shenyang reported more WFC than those in Chongqing, Wuhan, and Taiyuan; and urban residents in Lanzhou reported more than those in Chongqing and Wuhan. Meanwhile, urban residents in Chongqing, Lanzhou, Wuhan, and Taiyuan reported more WFE than those in Nanchang, Shenyang, and Guangzhou.

\subsection{Concurrent Validity}

It was hypothesized that WFC would be negatively associated with job satisfaction, marital satisfaction, and mental health, and positively associated with work stress; and that WFE would be positively associated with job satisfaction, marital satisfaction, and mental health, and negatively associated with work stress. The relationships between WFC, WFE, and criterion measures were assessed by calculating their Pearson product moment correlations with job satisfaction, CKMSS, mental health, and work stress.

As can be seen from Table 4, mild to moderate effect sizes were found between WFC and all the conceptually related scales (that is, job and marital satisfaction, mental health, and work stress) in the expected direction. Likewise, significant effect sizes in the small to moderate range were found between WFE and most of the conceptually related scales in 
Table 4 Relationships between work-family balance and criterion measures

\begin{tabular}{lccllll}
\hline & WFC & WFE & $\begin{array}{l}\text { Job } \\
\text { satisfaction }\end{array}$ & $\begin{array}{l}\text { Marital } \\
\text { satisfaction }\end{array}$ & $\begin{array}{l}\text { Mental } \\
\text { health }\end{array}$ & $\begin{array}{l}\text { Work } \\
\text { stress }\end{array}$ \\
\hline WFC & 1.00 & & & & & \\
WFE & .03 & 1.00 & & & & \\
Job satisfaction & $-.20^{* *}$ & $.14^{* *}$ & 1.00 & & & \\
Marital satisfaction & $-.13^{* *}$ & $.33^{* *}$ & $.10^{*}$ & 1.00 & & \\
Mental health & $-.31^{* *}$ & $.27^{* *}$ & $.30^{* *}$ & $.36^{* *}$ & 1.00 & \\
Work stress & $.23^{* *}$ & -.06 & $-.15^{* *}$ & -.02 & $-.26^{* *}$ & 1.00 \\
\hline$* p<.05 * * p<.01$ & & & & & &
\end{tabular}

the expected direction, except for work stress. These results provide preliminary evidence that the WFBS has good concurrent validity.

\section{Discussion and Conclusion}

The results of this study provide support for the two-factor structure of the WFBS, namely its components WFC and WFE, which implies that it is a multidimensional measurement. As conceptualized in the literature, work-family balance is derived from high WFE and low WFC, which is a formative rather than reflective latent construct (Edwards 2001). The short version, with 13 items, can fully capture the two-factor structure of work-family balance, as conceptualized in this study. The multidimensionality of the CWFB can also be revealed by the independent relationship between WFC and WFE $(r=.03, p>.05)$, which indicates that an increase in WFE does not mean a decrease in WFC; in other words, these two dimensions can coexist within a given individual, as previous findings suggest (Voydanoff 2004, 2005). It therefore seems unlikely that WFC and WFE have identical antecedents (Frone 2003; Grzywacz and Butler 2005) or similar consequences (Wayne et al. 2004).

This study also shows that both WFC and WFE have adequate internal consistency and good concurrent validity. The coefficient alpha for both is higher than that for the total scale, which suggests that the two subscales can be used separately with good reliability. Consistent with previous findings, WFC is found here to have a negative correlation with individual, interpersonal, and organizational functioning, as measured by mental health, marital and job satisfaction; and a positive correlation with work stress. Although the effect sizes are small, they all reach a significance level of .01. However, further study should extend this examination of concurrent validity by looking at its association with other indicators of wellbeing, such as overall stress (Frone 2000), family cohesion (Bond et al. 1998) and so on.

The findings indicate that there is no gender difference in either WFC or WFE, which may reflect the Chinese government's consistent support for the equal role and responsibility of husbands and wives for both family and work. The fact that middle-aged married adults and those with dependent children reported more WFC is consistent with role strain theory (Burr et al. 1979), which argues that the greater the role accumulation, the greater the demands and role incompatibility, and the greater role conflict and strain. Considering the different nature and pace of the economic development approaches taken across urban China, and the variations in the cultural values driving work-family balance, it is not 
surprising to see regional differences in both WFC and WFB. The present findings support the applicability of the Western work-family balance measure to urban China, and suggest that this concept has cross-cultural comparability in this global era.

Despite these findings, the present study has several limitations in terms of its external validity. First, the stability of the WFBS over time has not been tested. It is recommended that future studies investigate its test-retest reliability. Secondly, confirmatory factor analysis should be conducted with a new sample to test the factor structure of WFBS and provide further evidence for the validity of its constructs. Finally, most cities in this survey are regional capital cities in urban China. It will also be useful to assess this scale in the larger Chinese cities such as Beijing and Shanghai, where work and family role stress may be more salient, and which would certainly provide adequate comparison with other capital cities worldwide.

In summary, this study provides empirical support for the validity and reliability of the WFBS. Researchers and practitioners in both the family and industrial domains who are seeking an instrument to assess work-family balance may find it useful. Such an approach to measuring work-family balance, capturing as it does both WFC and WFE, has significant implications. For example, it may stimulate intervention researchers to think multidimensionally in evaluating strategies for promoting work-family balance and especially to balance work and family from a positive perspective. It may also prompt practitioners to consider both the individual and contextual antecedents that may serve as barriers or facilitators to achieve a work-family balance, hence supporting the implementation of family-friendly policies in general management practice. Thirdly, as this measure has only 13 items, it is convenient to administer, making it easier to identify specific problems in balancing work and family.

Open Access This article is distributed under the terms of the Creative Commons Attribution Noncommercial License which permits any noncommercial use, distribution, and reproduction in any medium, provided the original author(s) and source are credited.

\section{References}

Allen, T. D., Herst, D. E., Bruck, C. S., \& Sutton, M. (2000). Consequences associated with work-to-family conflict: A review and agenda for future research. Journal of Occupational Health Psychology, 5, 278-308.

Aryee, S., Srinivas, E. S., \& Tan, H. H. (2005). Rhythms of life: Antecedents and outcomes of work-family balance in employed parents. Journal of Applied Psychology, 90, 132.

Barnett, K. A., Del Campo, R. L., Del Campo, D. S., \& Steiner, R. L. (2004). Work and family balance among dual-earner working class Mexican-Americans: Implications for therapists. Contemporary Family Therapy, 25, 353-366.

Behson, S. J. (2002). Coping with family-to-work conflict. Journal of Occupational Health Psychology, 7 , 324-341.

Bond, J. T., Galinsky, E., \& Swanberg, J. E. (1998). The national study of the changing workforce. New York: Families and Work Institute.

Burr, W. R., Leigh, G. K., Day, R. D., \& Constantine, J. (1979). Symbolic interaction and the family. In W. R. Burr, R. Hill, F. I. Nye, \& I. Reiss (Eds.), Contemporary theories about the family (Vol. 2, pp. 42-111). New York: Free Press.

Carlson, D. S., Kacmar, K. M., \& Willams, L. J. (2000). Construction and validation of a multidimensional measure of work-family conflict. Journal of Vocational Behavior, 56, 249-276.

Carlson, D. S., Kacmar, K. M., Wayne, J. H., \& Grzywacz, J. G. (2006). Measuring the positive side of the work-family interface: Development and validation of a work-family enrichment scale. Journal of Vocational Behavior, 68, 131-164.

Cattell, R. B. (1966). The scree test for the number of factors. Multivariate Behavioral Research, 1, 245. 
Du, F. L., \& Dong, X. Y. (2008). Women's labor force participation and childcare choices in urban China during the economic transition. Retrieved from http://www.cwe.org.cn/info/article. asp?articleid=367.

Edwards, J. R. (2001). Multidimensional construct in organizational behavior research: An integrative analytic framework. Organizational Research Methods, 4, 144-192.

Frone, M. R. (2000). Work-family conflict and employee psychiatric disorders: The National Comorbidity Survey. Journal of Applied Psychology, 85, 888-895.

Frone, M. R. (2003). Work-family balance. In J. C. Quick \& L. E. Tetrick (Eds.), Handbook of occupational health psychology (pp. 143-162). Washington, DC: American Psychological Association.

Frone, M. R., Russell, M., \& Cooper, M. L. (1997). Relation of work-family conflict to health outcomes: A four-year longitudinal study of employed parents. Journal of Occupational Organizational Psychology, $70,325-335$.

Gornick, J. C., Heron, A., \& Eisenbrey, R. (2007). The work-family balance: An analysis of European, Japanese, and US Work-Time Policies. (Briefing paper \#189, Economic Policy Institute).

Grzywacz, J. G., \& Bass, B. L. (2003). Work, family, and mental health: Testing different models of workfamily fit. Journal of Marriage and Family, 65, 248-261.

Grzywacz, J. G., \& Butler, A. B. (2005). The impact of job characteristics on work-to-family facilitation: Testing a theory and distinguishing a construct. Journal of Occupational Health Psychology, 10, 97-109.

Grzywacz, J. G., \& Carlson, D. S. (2007). Conceptualizing work-family balance: Implications for practice and research. Advances in Developing Human Resources, 9, 455-471.

Halpern, D. F. (2005). Psychology at the intersection of work and family: Recommendations for employers, working families, and policymakers. American Psychologist, 60, 397-409.

Kossek, E. E., \& Ozeki, C. (1999). Bridging the work-family policy and productivity gap: A literature review. Community work \& Family, 2, 139-149.

Lai, G. (1995). Work and family roles and psychological well-being in urban China. Journal of Health and Social Behavior, 36, 11-37.

Li, H., \& Chen, Q. F. (2002). Normative data of the Chinese Kansas Marital Satisfaction scale: Findings based on Hong Kong and Beijing Samples. Psychological Development and Education, 4, 82-85.

Lu, J. F., Siu, O. L., Spector, P. E., \& Shi, K. (2009). Antecedents and outcomes of a fourfold taxonomy of workfamily balance in Chinese employed parents. Journal of Occupational Health Psychology, 14, 182-192.

Major, V. S., Klein, K. J., \& Ehrhart, M. G. (2002). Work time, work interference with family, and psychological distress. Journal of Applied Psychology, 87, 427-436.

Marshall, N. L., \& Barnett, R. C. (1991). The relationship between women's work and family role and their subjective well-being and psychological distress. In M. Frankenhaeuser, U. Lundberg, \& M. Chesney (Eds.), Women, work and health: Stress and opportunities (pp. 111-136). New York: Plenum.

Marshall, N. L., \& Barnett, R. C. (1993). Work-family strains and gains among two-earner couples. Journal of Community Psychology, 21, 64-78.

McGinnity, F., \& Whelan, C. T. (2009). Comparing work-life conflict in Europe: Evidence from the European social survey. Social Indicators Research, 93, 433-444.

Netemeyer, K. R., Bibeau, J. S., \& McMurrian, R. (1996). Development and validation of work-family conflict and family-work conflict scales. Journal of Applied Psychology, 81, 400-410.

Siu, O., Spector, P., Cooper, C., \& Lu, C. (2005). Work stress, self-efficacy, Chinese work values, and work well-being in Hong Kong and Beijing. International Journal of Stress Management, 12(3), 274-288.

Spector, P. E., Allen, T. D., Poelmans, S., Lapierre, L. M., Cooper, C. L., O’Driscoll, M., et al. (2007). Cross-national differences in relationships of work demands, job satisfaction and turnover intentions with work-family conflict. Personnel Psychology, 60, 805-835.

Tabachnick, B. G., \& Fidell, L. S. (2001). Using multivariate statistics (4th ed.). Needham Heights, MA: Allyn \& Bacon.

Voydanoff, P. (2004). The effects of work demands and resources on work-to-family conflict and facilitation. Journal of Marriage and Family, 66, 398-412.

Voydanoff, P. (2005). Toward a conceptualization of perceived work-family fit and balance: A demands and resources approach. Journal of Marriage and Family, 67, 822-836.

Wanous, J. P., et al. (1997). Overall job satisfaction: How good are single-item measures? Journal of Applied Psychology, 82, 247-252.

Ware, J. (2000). Sf-36 health survey update. Spine, 25, 3130-3139.

Wayne, J. H., Musisca, N., \& Fleeson, W. (2004). Considering the role of personality in the work-family experience: Relationships of the big five to work-family conflict and facilitation. Journal of Vocational Behavior, 64, 108-130.

Wooden, M. (2003). Balancing work and family at the start of the 21st century: Evidence from wave 1 of the HILDA survey. (Paper presented to the Pursing Opportunity and Prosperity: The 2003 Melbourne Institute Economic and Social Outlook Conference, Melbourne). 